This item was submitted to Loughborough's Institutional Repository (https://dspace.lboro.ac.uk/) by the author and is made available under the following Creative Commons Licence conditions.

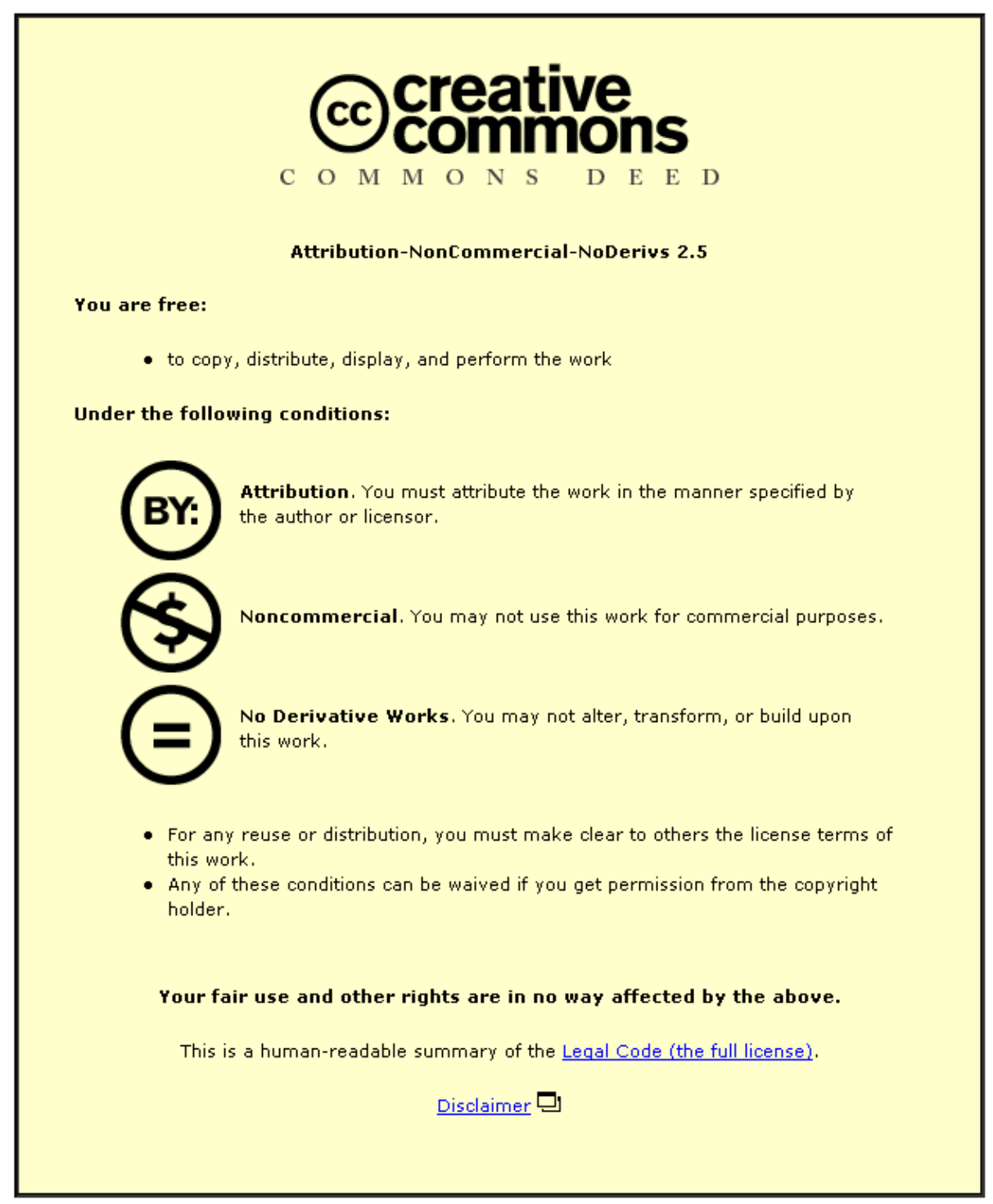

For the full text of this licence, please go to: http://creativecommons.org/licenses/by-nc-nd/2.5/ 


\title{
Possible shortcomings of the calibration methods for certain non-destructive monitoring devices for helically wound steel cables
}

\author{
M Raoof* and T J Davies \\ Civil and Building Engineering Department, Loughborough University, Loughborough, UK
}

The manuscript was received on 19 January 2005 and was accepted after revision for publication on 18 November 2005.

DOI: 10.1243/03093247JSA110

\begin{abstract}
Coupled extensional-torsional behaviour of axially pre-loaded helically wound steel cables (wire ropes and/or spiral strands) under specific forms (i.e. unit-step, triangular, and half-sine) of impact loading are considered in some detail. The final closed-form formulations can handle both the no-slip and/or the traditionally used full-slip coupled extensional/torsional constitutive equations for helically wound cables, and describe the various characteristics of the resulting pairs of axial or torsional waves at any location along the cable with one end fixed against movement and the other end subjected to impact loading. By using extensive numerical results, which cover the full range of current manufacturing limits for the lay angle (with this being the sole controlling geometrical parameter as far as the axial/torsional stiffnesses are concerned), it is shown that significant differences exist between a number of axial/torsional wave characteristics, depending on whether the no-slip or the full-slip version of the constitutive relations is used in the analysis. It is demonstrated that modest increases in the magnitudes of the lay angles can lead to significant increases in the differences between the no-slip and the full-slip wave propagation characteristics. The present findings may have significant practical implications in relation to the currently adopted techniques used by industry for calibrating the electronic boxes, which are subsequently used as permanently installed devices, for the in situ detection of individual wire fractures under, say, fatigue loading associated with cable-supported structures.
\end{abstract}

Keywords: wire ropes, spiral strands, friction, stiffness, axial, torsional, impact loading, non-destructive methods, bridges, overhead transmission lines

\section{INTRODUCTION}

In recent years, there has been a growing need for progressively larger diameter steel cables (wire ropes and/or spiral strands) for the new generation of cable-supported bridges. Larger and longer wire ropes and spiral strands have also been used (as, for example, moorings) in offshore applications. The traditional methods of cable analysis and design are based largely on practical experience relating to significantly smaller diameter cables, and, therefore, there has been a pressing need for their re-examination.

\footnotetext{
* Corresponding author: Civil and Building Engineering Department, Loughborough University, Leicestershire LE11 3TU, UK. email: m.raoof@lboro.ac.uk
}

Over the past, say, 25 years, substantial improvements have been made in the understanding of the behaviour of helically wound steel cables, in which the term 'cables' includes spiral strands and wire ropes. Spiral strand, or strand, is (in British parlance) a group of wires laid helically in successive layers over a straight central King wire (or an equal lay core). Wire rope consists of (typically) six strands laid helically over a central core, which may itself consist of twisted fibres or a smaller independent wire rope. Unlike the individual wires in a wire rope which are laid as double helices, the wires in a spiral strand follow a simple helical path with lay angle, $\alpha$. Wire rope is, therefore, a little more axially flexible than a spiral strand, but much more flexible in bending. This higher bending flexibility is, of course, the reason why wire ropes (instead of spiral strands) are 
so widely used as tractive elements over pulleys, winch drums, and fairleads in various applications. Spiral strands, on the other hand, are often employed as, for example, hangers in suspension bridges or stays in cable-stayed bridges.

The orthotropic sheet theory has previously been reported by Raoof and his associates (for example, see references [1-3]) for obtaining reliable estimates of the coupled axial-torsional stiffnesses for axially pre-loaded spiral strands, which have been found to vary between the two limiting values of full-slip and no-slip, as a function of the external axial and/or torsional load perturbations superimposed on a mean axial load. Very briefly, the axial and torsional stiffnesses for small load changes have been shown to be significantly larger than for large load changes, because small external axial and/or torsional load disturbances do not induce interwire slippage. In the presence of interwire friction, and for sufficiently small external load disturbances (which, for example, in the axial case, correspond to axial load range-mean axial load ratios less than, say, 2 per cent [2]), the wires stick together, and the axially pre-loaded spiral strand will effectively behave as a solid rod (with allowance being made for the presence of gaps between the individual wires); these conditions are known as the no-slip regime. When large variations in the external load take place, with its associated large changes in the interwire contact forces within the various layers of helical wires, the tangential force changes between the round wires in line-contact will be large enough to overcome interwire friction and induce sliding movements on the interwire line-contact patches; these conditions are known as the full-slip regime. Obviously, a large number of axial stiffness results have traditionally been provided by the cable manufacturers based on their shop measurements, but because of the large load ranges involved, such results invariably relate to the full-slip axial stiffness in the present terminology.

The carefully conducted and large-scale experiments of Strzemiecki and Hobbs [4] have demonstrated that axially pre-loaded wire ropes with independent wire rope cores (IWRC) also exhibit the no-slip and/or full-slip stiffness characteristics. Guided by this observation, Raoof and Kraincanic [3] have developed a theoretical model for predicting the coupled no-slip and/or full-slip axial-torsional stiffness coefficients for axially pre-loaded wire ropes with IWRC, with encouraging correlations found between the predictions based on this model and the test data reported by others [5]. This is in contrast to the predictions based on the invariably frictionless thin rod models of Costello and his associates (e.g. $[\mathbf{6}, 7])$, Velinsky $[\mathbf{8}]$, and Jiang [9], with these models only leading to predictions of the full-slip (in the present terminology) coupled axial-torsional stiffness coefficients, with their predictions for large diameter wire ropes with IWRC not correlating well with experimental results (e.g. see [3]).

Helically wound steel cables are used in many cases (e.g. aircraft landing arresting gears in naval aircraft carriers) to resist impact loads, and until fairly recently the classical approaches to the dynamic problem for taut lines ignored the torsional effects associated with the axial loading (e.g. [10-12]). It was Samras and his associates $[\mathbf{1 3}, \mathbf{1 4}]$ who first pointed out the importance of taking the coupled extensionaltorsional behaviour of wire ropes under dynamic loading conditions into account. In their work, Samras and his associates did not use any theoretical means of obtaining the stiffness matrix for wire ropes but made use of experimentally obtained constitutive constants in their dynamic analysis. In particular, they only addressed the full-slip case which relates to conventional static load-deformation behaviour. Phillips and Costello [15] used an idealized frictionless model of a single-layer spiral strand with no core wire to investigate the axial (and associated rotational) response of the steel cable to impact loading. Leech and Overington [16] used a different technique to solve the basic equations for frictionless cables derived in reference [15]. Unlike reference [15], Leech and Overington [16] also conducted some experiments on single-layer strands which appeared to support their theory in a qualitative manner. In a recent paper, Martin and Berger [17] used the constitutive relationships for frictionless multilayered spiral strands, based on the semi-continuous model of Cardou and his associates (e.g. $[\mathbf{1 8}]$ ), to give a better insight into the problem of wave propagations in spiral strands, taking the coupled axial-torsional behaviour into account.

Raoof et al. [19] followed the general approach recommended by Jiang et al. [20] to develop closedform solutions for predicting the extensionaltorsional wave speeds and displacements in axially pre-loaded spiral strands experiencing specific forms of impact loading at one end with the other end fixed; the impact loading functions considered in reference [19] were of the unit-step and the triangular type. Raoof et al. [19] argued that unlike the traditional methods that had invariably assumed a unique (full-slip) force-displacement stiffness matrix, the ever-present interwire friction necessitates the use of an alternative (no-slip) stiffness matrix for 
sufficiently small levels of external load disturbances in the presence of substantial levels of mean axial load in fully bedded-in helically wound cables. In particular, numerical results for a $39 \mathrm{~mm}$ outside diameter multilayered spiral strand as reported by Raoof et al. [19] strongly suggested the significant difference that the use of no-slip constitutive relations (instead of the traditionally used full-slip values) can make to the pattern of extensional-torsional wave speeds and deformations in axially pre-loaded spiral strands subjected to small levels of impact loading. As fully discussed later, such cases are of relevance to the in-service (non-destructive) methods for wire fracture detection in cables subjected to, say, axial fatigue loading: in such cases, the fracture of an individual wire within a helically wound cable applies a small (but measurable) form of impact loading on the cable whose resulting coupled axial-torsional waves are picked up by non-destructive detection devices whose output signals may be significantly affected by the higher levels of stiffness in connection with the no-slip cable characteristics.

Although the specific type of impact loading induced as a result of an individual wire fracture in a helically wound cable is (at least for the present) extremely difficult (if at all possible) to identify with any degree of certainty, a reasonable insight may be obtained into the patterns of extensional-torsional wave speeds and deformations within an axially preloaded cable by considering the solutions for a range of different types of impact loading functions. In what follows, by using the same approach as that adopted by Raoof et al. [19], who addressed the cases of unit-step and triangular impact loading functions, closed-form formulations will be reported for the case of a half-sine impact loading function, hence enabling the numerical results to be compared for a wide range of impact loading functions.

Moreover, theoretical parametric studies reported by Raoof [21], which covered a wide range of spiral strand (and wire) diameters, lay angles, number of wires in each layer, and number of layers of helical wires, have demonstrated that the full-slip coupled axial-torsional stiffnesses of multilayered spiral strands are a sole function of the lay angles in the various layers, with the other geometrical parameters having a secondary influence on the spiral strand's axial-torsional stiffnesses. Similar extensive theoretical parametric studies reported by Raoof and Kraincanic [22], on the other hand, have strongly suggested that the no-slip coupled axial-torsional stiffnesses only depend on the lay angles in various layers and the level of mean axial strain on the spiral strand, with wide variations (within the current manufacturing limits) in the other geometrical parameters having a secondary influence on the no-slip coupled axial-torsional stiffnesses.

As regards the new developments as reported in the present paper, bearing in mind the first-order (controlling) role of the lay angle on the no-slip and/or full-slip coupled axial-torsional stiffnesses, in what follows, by using the constructional details for three different $127 \mathrm{~mm}$ outside diameter (i.e. realistic) spiral strands with lay angles of 12,18 , and $24^{\circ}$ (as designed and made available to the first author, some years ago, by the wire rope manufacturer 'Bridon Ropes'), numerical results will be presented that will demonstrate the controlling (i.e. first-order) effect of the lay angle on the no-slip and/or full-slip coupled axial-torsional wave propagation characteristics of axially pre-loaded spiral strands experiencing a range of different impact loading functions (i.e. unitstep, triangular, and half-sine), with the presently adopted range of lay angles (i.e. $12-24^{\circ}$ ) very nearly covering the full range of lay angles as currently offered by the manufacturers. Such results will then be used to highlight the possible shortcomings of calibration methods currently used for certain nondestructive monitoring 'electronic boxes' for the detection of individual wire fractures under service conditions in, say, bridging applications, as well as overhead transmission lines (among others). As a prerequisite to this, the next section will present (for completeness) the salient features of the theoretical model of Raoof et al. [19] for unit-step and triangular impact loading functions with the theoretical formulations extended to include the half-sine impact loading case (with this being a new development). In what follows, inclusion of the final formulations for the unit-step and triangular loading functions not only provides the present authors with the opportunity to correct certain minor typographical errors in some of the final formulations as presented in reference [19] but also enables the reader to better understand (and appreciate) the subsequent developments.

\section{THEORY}

\subsection{Constitutive relations for helically wound steel cables}

This topic has been addressed in considerable detail elsewhere [1, 21-24]. For the extreme cases of either no-slip and/or full-slip, for the constitutive equations relating the cable tension, $F$, and torque, $M$, to the 
cable deformations, it has been postulated that

$$
\begin{aligned}
& F=A_{1} \varepsilon+A_{2} \Gamma \\
& M=A_{3} \varepsilon+A_{4} \Gamma
\end{aligned}
$$

where $A_{1}, A_{2}, A_{3}$, and $A_{4}$ are constitutive constants dependent on both the cable material and construction. In equations (1) and (2), $\varepsilon=$ axial strain $=$ $\partial u / \partial x$ and $\Gamma=$ twist per unit length $=\partial \theta / \partial x$.

Experimental measurements have verified the postulated linear form of the constitutive equations for the full-slip case. In particular, it is shown that within experimental accuracy, $A_{2} \approx A_{3}$, which is compatible with the Maxwell-Betti reciprocal theorem for linear elastic structures. Raoof and Hobbs [1, 23] provide accurate (although mathematically rather complex) means of obtaining the no-slip and fullslip predictions of $A_{1}-A_{4}$ for axially pre-loaded spiral strands, while Raoof and Kraincanic [3] give a detailed account of a theoretical model for estimating the no-slip and full-slip values of $A_{1}-A_{4}$ for axially preloaded wire ropes with an independent wire rope core. It should be noted that reasonably accurate values of the full-slip $A_{1}-A_{4}$ coefficients for axially preloaded spiral strands may also be obtained by the very simple (hand-based) formulations reported by Raoof [21]. As regards simple determination of the no-slip stiffness coefficients, however, although Raoof and Kraincanic [22] have, on the basis of extensive theoretical parametric studies, already reported simple (hand-based) formulations for determining the no-slip $A_{1}-A_{4}$ stiffness coefficients for axially preloaded spiral strands, due to the subtle variations of the lay angles in various layers of the usually nominally torsionally balanced spiral strands in practice (which is based on commercially confidential experience), only their simple estimates of the coefficients $A_{1}$ and $A_{4}$ are (for torsionally balanced spiral strands) sufficiently accurate for use in the impact loading formulations reported in the following sections. As pointed out by Raoof and Kraincanic [22], their simple estimates of the no-slip $A_{2}$ and $A_{3}$ stiffness coefficients do not enjoy general reliability. For the present purposes, therefore, the only means of obtaining accurate estimates of the $A_{2}$ and $A_{3}$ stiffness coefficients (as defined by Raoof and Kraincanic [22]) is by using the complex formulations of Raoof and Hobbs [1, 23]. For more information about this point, the interested reader may refer to reference [24].

Finally, as discussed in the previous section, for a given cable construction, the full-slip stiffness coefficients have been found to be, for all practical purposes, independent of the cable mean axial load, with the no-slip stiffness coefficients being a function of the mean axial tension on the helically wound cable.

\subsection{Dynamic analysis}

\subsubsection{Equations of motion}

The equations of motion for a coupled system with constitutive relations, as defined in the previous section, are $[13]$

$$
\begin{aligned}
& m \frac{\partial^{2} u}{\partial t^{2}}=A_{1} \frac{\partial^{2} u}{\partial x^{2}}+A_{2} \frac{\partial^{2} \theta}{\partial x^{2}} \\
& I \frac{\partial^{2} \theta}{\partial t^{2}}=A_{3} \frac{\partial^{2} u}{\partial x^{2}}+A_{4} \frac{\partial^{2} \theta}{\partial x^{2}}
\end{aligned}
$$

where $\theta$ is the angular rotation of the cable whose longitudinal displacement is $u$ and $t=$ time. For a spiral strand, $m$ is the mass per unit length

$$
m=A_{\mathrm{s}} \rho
$$

with $\rho$ being the density of steel and $A_{\mathrm{s}}$ denoting the net area of the steel (including the core wires) [19], while $I$ is the mass moment about the strand axis, per unit length of the structure in the unloaded configuration

$$
I=2 I_{x x} \rho
$$

where

$$
\begin{aligned}
I_{x x} & =\sum_{i=1}^{N} I_{n i} \\
& =\sum_{i=1}^{N}\left\{\frac{\pi^{2}}{256}\left[\left(2 r_{i}+D_{i}\right)^{4}-\left(2 r_{i}-D_{i}\right)^{4}\right]\right\}
\end{aligned}
$$

In the above, $N$ denotes the total number of layers in a spiral strand excluding the core wire(s), with $i=1$ for the outermost layer. Equation (6) assumes that for spiral strands with, say, $N \geqslant 2$, the contribution of the core wire(s) to $I_{x x}$ is sufficiently small to be ignored.

\subsubsection{Response to impact loading}

Jiang et al. [20] considered a coupled system, with one end fixed at $x=0$ and subjected to sinusoidal forms of the excitation functions for axial force $F_{0}(t)$ and torque $M_{0}(t)$ at the other end $x=h$, assuming the following boundary conditions

$$
\begin{aligned}
& u(0, t)=0, \quad \theta(0, t)=0 \\
& A_{1} \frac{\partial u}{\partial x}+\left.A_{2} \frac{\partial \theta}{\partial x}\right|_{x=h}=F_{0}(t) \\
& A_{3} \frac{\partial u}{\partial x}+\left.A_{4} \frac{\partial \theta}{\partial x}\right|_{x=h}=M_{0}(t)
\end{aligned}
$$


while at time $t=0$ there was assumed to be no motion, with the associated boundary conditions

$$
\begin{aligned}
& u(x, 0)=0, \quad \theta(x, 0)=0 \\
& \frac{\partial u(x, 0)}{\partial t}=0, \quad \frac{\partial \theta(x, 0)}{\partial t}=0
\end{aligned}
$$

For the above boundary conditions, the solution to the equations of motion [i.e. equations (3) and (4)] is given by Jiang et al. [20] as

$$
\begin{aligned}
& u(x, t)=\sum_{i=1}^{2}\left[a_{i} F_{i}(x, t)+c_{i} M_{i}(x, t)\right] \\
& \theta(x, t)=\sum_{i=1}^{2}\left[b_{i} F_{i}(x, t)+d_{i} M_{i}(x, t)\right]
\end{aligned}
$$

with

$$
\begin{aligned}
F_{i}(x, t)= & \frac{4 \omega_{i}}{\pi} \sum_{n=0}^{\infty} \frac{(-1)^{n}}{2 n+1} \sin \frac{(2 n+1) \pi x}{2 h} \\
& \times \int_{0}^{t} F_{0}(t-z) \sin \frac{(2 n+1) \pi z}{2 \omega_{i}} \mathrm{~d} z
\end{aligned}
$$

and

$$
\begin{aligned}
M_{i}(x, t)= & \frac{4 \omega_{i}}{\pi} \sum_{n=0}^{\infty} \frac{(-1)^{n}}{2 n+1} \sin \frac{(2 n+1) \pi x}{2 h} \\
& \times \int_{0}^{t} M_{0}(t-z) \sin \frac{(2 n+1) \pi z}{2 \omega_{i}} \mathrm{~d} z
\end{aligned}
$$

where

$$
\begin{aligned}
& a_{i}=\frac{1}{2 m h}\left[1 \pm \frac{I A_{1}-m A_{4}}{\sqrt{\left(I A_{1}-m A_{4}\right)^{2}+4 m I A_{2} A_{3}}}\right] \\
& b_{i}=\frac{ \pm A_{3}}{h \sqrt{\left(I A_{1}-m A_{4}\right)^{2}+4 m I A_{2} A_{3}}} \\
& c_{i}=\frac{ \pm A_{2}}{h \sqrt{\left(I A_{1}-m A_{4}\right)^{2}+4 m I A_{2} A_{3}}}
\end{aligned}
$$

In the above, $i=1,2$, with the positive and negative signs in equations (17) to (19) corresponding to cases with $i=1$ and $i=2$ respectively, and

$$
\begin{aligned}
& d_{i}=\frac{1}{2 I h}\left[1 \mp \frac{I A_{1}-m A_{4}}{\sqrt{\left(I A_{1}-m A_{4}\right)^{2}+4 m I A_{2} A_{3}}}\right] \\
& \omega_{i}^{2}=\frac{h^{2}\left[\left(I A_{1}+m A_{4}\right) \mp \sqrt{\left(I A_{1}-m A_{4}\right)^{2}+4 m I A_{2} A_{3}}\right]}{2\left(A_{1} A_{4}-A_{2} A_{3}\right)}
\end{aligned}
$$

where $i=1,2$, with the negative and positive signs in equations (20) and (21) corresponding to cases with $i=1$ and $i=2$ respectively. Thus, for a given excitation, i.e. with $F_{0}(t)$ and $M_{0}(t)$ defined, the values of $u(x, t)$ and $\theta(x, t)$ may be found.

In what follows, three different types of impact loading functions of the general form

$$
\begin{aligned}
& F_{0}(t)=F_{0} g(t) \\
& M_{0}(t)=M_{0} g(t)
\end{aligned}
$$

are considered, where $F_{0}$ and $M_{0}$ are the amplitudes of the external load disturbances. Three distinctly different cases of $g(t)$ are used. In the first instance, a unit-step function for $g(t)$ defined as

$$
g(t)= \begin{cases}1, & 0 \leqslant t \leqslant A \\ 0, & A<t<\infty\end{cases}
$$

is assumed. Using equations (22), (23), and (24a) and (24b), the following has been found by Raoof et al. [19]

$$
\begin{aligned}
& u(x, t)=\sum_{i=1}^{2}\left(F_{0} a_{i}+M_{0} c_{i}\right) w_{i}(x, t) \\
& \theta(x, t)=\sum_{i=1}^{2}\left(F_{0} b_{i}+M_{0} d_{i}\right) w_{i}(x, t)
\end{aligned}
$$

with

$$
\begin{aligned}
w_{i}(x, t)= & \left(\frac{4 \omega_{i}}{\pi}\right)^{2} \sum_{n=0}^{\infty} \frac{(-1)^{n}}{(2 n+1)^{2}} \\
& \times \sin \frac{(2 n+1) \pi A}{4 \omega_{i}} \sin \frac{(2 n+1) \pi x}{2 h} \\
& \times \sin \frac{(2 n+1) \pi(2 t-A)}{4 \omega_{i}}, \quad i=1,2
\end{aligned}
$$

In the above, $A$ is the duration of the impact loading and $h$ is the length of the cable.

For a triangular impact function, $g(t)$ in equations (22) and (23) may be expressed in the form

$$
g(t)= \begin{cases}\frac{-1}{A}(t-A), & 0 \leqslant t \leqslant A \\ 0, & A<t<\infty\end{cases}
$$

The solution for $u(x, t)$ and $\theta(x, t)$ can be expressed in the same form as those in equations (25) and (26) 
with the formulations for parameter $w_{i}(x, t)$ given as

$$
\begin{aligned}
w_{i}(x, t)=\sum_{n=0}^{\infty} & \sin \frac{(2 n+1) \pi x}{2 h} \\
\times & \quad\left\{\left[\frac{\left(4 \omega_{i}\right)^{3}(-1)^{n}}{2 A(2 n+1)^{3} \pi^{3}} \cos \frac{(2 n+1)(2 t-A) \pi}{4 \omega_{i}}\right.\right. \\
& \left.\quad \times \sin \frac{(2 n+1) \pi A}{4 \omega_{i}}\right] \\
& +\frac{\left(4 \omega_{i}\right)^{2}(-1)^{n}}{(2 n+1)^{2} \pi^{2}} \sin \left[\frac{(2 n+1) \pi A}{4 \omega_{i}}\right] \\
& \times \sin \left[\frac{(2 n+1) \pi}{4 \omega_{i}}(2 t-A)\right] \\
& \left.-\frac{8 \omega_{i}^{2}(-1)^{n}}{(2 n+1)^{2} \pi^{2}} \cos \frac{(2 n+1)(t-A) \pi}{2 \omega_{i}}\right\}
\end{aligned}
$$

Alternatively, for a half-sine impact function, $g(t)$ in equations (22) and (23) may be expressed in the form

$$
g(t)= \begin{cases}\sin \frac{\pi t}{A}, & 0<t<A \\ 0, & A<t<\infty\end{cases}
$$

The solution for $u(x, t)$ and $\theta(x, t)$ can also be expressed in the same form as those in equations (25) and (26), with the parameter $w_{\mathrm{i}}(x, t)$, for this form of impact loading function, in equations (25) and (26), given by

$$
\begin{aligned}
w_{i}(x, t)= & \frac{8 A \omega_{i}}{\pi^{2}} \sum_{n=0}^{\infty} \frac{(-1)^{n}}{(2 n+1)\left\{1-\left[(2 n+1) A /\left(2 \omega_{i}\right)\right]^{2}\right\}} \\
& \times \cos \frac{(2 n+1) \pi A}{4 \omega_{i}} \sin \frac{(2 n+1) \pi x}{2 h} \\
& \times \sin \frac{(2 n+1) \pi(2 t-A)}{4 \omega_{i}}
\end{aligned}
$$

(a) Speed of axial and torsional waves. For the unit-step, triangular, and half-sine impact loading functions, the equations defining $w_{i}(x, t)$ may be rewritten in alternative forms. For the unit-step impact loading function, the alternative form of equation (27) is given as

$$
\begin{aligned}
w_{i}(x, t)= & \sum_{n=0}^{\infty} \frac{2(-1)^{n}}{\lambda_{i}^{2}} \sin \frac{\lambda_{i} A}{2} \\
& \times\left\{\cos \left[k x-\lambda_{i}\left(t-\frac{A}{2}\right)\right]\right. \\
& \left.\quad-\cos \left[k x+\lambda_{i}\left(t-\frac{A}{2}\right)\right]\right\}
\end{aligned}
$$

where

$$
k=\frac{(2 n+1) \pi}{2 h}
$$

and

$$
\lambda_{i}=\frac{(2 n+1) \pi}{2 \omega_{i}}, \quad i=1,2
$$

The speeds of either the axial or the torsional waves, $C_{1}$ and $C_{2}$, are given by

$$
C_{i}=\frac{\lambda_{i}}{k}, \quad i=1,2
$$

or

$$
C_{i}=\frac{h}{\omega_{i}}, \quad i=1,2
$$

For the triangular impact loading function, on the other hand, equation (29) may be rewritten as

$$
\begin{aligned}
w_{i}(x, t)=\sum_{n=0}^{\infty} \frac{(-1)^{n}}{\lambda_{i}^{2}}\left(\frac{2}{A \lambda_{i}}\right. & \sin \left(\frac{\lambda_{i} A}{2}\right) \\
\times & \left\{\sin \left[k x-\lambda_{i}\left(t-\frac{A}{2}\right)\right]\right. \\
& \left.+\sin \left[k x+\lambda_{i}\left(t-\frac{A}{2}\right)\right]\right\} \\
+ & 2 \sin \left(\frac{\lambda_{i} A}{2}\right) \\
\times & \left\{\cos \left[k x-\lambda_{i}\left(t-\frac{A}{2}\right)\right]\right. \\
& \left.-\cos \left[k x+\lambda_{i}\left(t-\frac{A}{2}\right)\right]\right\} \\
- & \left\{\sin \left[k x-\lambda_{i}(t-A)\right]\right. \\
& \left.\left.+\sin \left[k x+\lambda_{i}(t-A)\right]\right\}\right)
\end{aligned}
$$

For the half-sine impact loading function, the alternative form of equation (31) is given as

$$
\begin{array}{r}
w_{i}(x, t)=\frac{4 A \omega_{i}}{\pi^{2}} \sum_{n=0}^{\infty} \frac{(-1)^{n}}{(2 n+1)\left\{1-\left[(2 n+1) A /\left(2 \omega_{i}\right)\right]^{2}\right\}} \\
\times \cos \frac{\lambda_{i} A}{2}\left\{\cos \left[k x-\lambda_{i}\left(t-\frac{A}{2}\right)\right]\right. \\
\left.\quad-\cos \left[k x+\lambda_{i}\left(t-\frac{A}{2}\right)\right]\right\}
\end{array}
$$


As expected, the speeds of wave propagations do not depend on the type of externally applied impact loading, and the values of $C_{1}$ as well as $C_{2}$ for either the axial or the torsional waves are the same for the unit-step, triangular, and half-sine impact loading functions. It should be noted that if there is a torsional wave, propagating at speed $C$, then it will be accompanied by an axial wave propagating at the same speed and with the same shape, but with a different amplitude [17]; in other words, there are two possible torsional waves with speeds $C_{1}$ and $C_{2}$ associated with which there are two axial waves with speeds $C_{1}$ and $C_{2}$ respectively.

Finally, the ratios of torsional to extensional amplitudes, $R_{1}$ and $R_{2}$, are [13]

$$
R_{1,2}=\frac{\theta}{u}=\frac{m C_{1,2}^{2}-A_{1}}{A_{2}}
$$

In the above, $R_{1}$ relates to torsional and axial waves, both of which have speed $C_{1}$, and $R_{2}$ relates to torsional and axial waves, both of which have speed $C_{2}$.

\section{RESULTS}

Numerical results have been obtained for three different $127 \mathrm{~mm}$ outside diameter axially pre-loaded multilayered spiral strands: the three strand constructions have lay angles of $12^{\circ}, 18^{\circ}$, and $24^{\circ}$, with their other geometrical parameters kept very nearly the same. The construction details for these three strands are given in Tables 1 to 3 .

For the present purposes, the spiral strands are all assumed to be $10 \mathrm{~m}$ in length, with the three $127 \mathrm{~mm}$ spiral strands experiencing a mean axial strain $S_{1}^{\prime}=0.002867$, which roughly corresponds to one-third of their ultimate tensile strengths. The Young's modulus for steel $E_{\mathrm{s}}=200 \mathrm{kN} / \mathrm{mm}^{2}$ and the corresponding Poisson's ratio $v=0.28$, with the density of steel $\rho=7850 \mathrm{~kg} / \mathrm{m}^{3}$.

The full-slip and no-slip constitutive constants for the three $127 \mathrm{~mm}$ outside diameter spiral strands, as calculated using the more accurate (but complex) version of the orthotropic sheet theory as reported by Raoof and Hobbs [1, 23], are given in Table 4, where, $d_{1}=A_{1} / E_{\mathrm{s}}, d_{2}=A_{2} / E_{\mathrm{s}}, d_{3}=A_{3} / E_{\mathrm{s}}$, and $d_{4}=A_{4} / E_{\mathrm{s}}$. It

Table 1 Construction details for the $127\left(\alpha=12^{\circ}\right) \mathrm{mm}$ outside diameter spiral strand

\begin{tabular}{lllllll}
\hline Layer & $\begin{array}{l}\text { Number of } \\
\text { wires } n\end{array}$ & Lay direction & $\begin{array}{l}\text { Wire diameter } \\
D(\mathrm{~mm})\end{array}$ & $\begin{array}{l}\text { Lay angle } \\
(\mathrm{deg})\end{array}$ & $\begin{array}{l}\text { Pitch circle radius } \\
\text { (theoretical) } r(\mathrm{~mm})\end{array}$ & $\begin{array}{l}\text { Net steel area } \\
A_{\mathrm{n} i}\left(\mathrm{~mm}^{2}\right)\end{array}$ \\
\hline 1 & 56 & RH & 6.60 & 12.00 & 60.17 & 1958.67 \\
2 & 50 & LH & 6.60 & 12.00 & 53.73 & 1748.81 \\
3 & 44 & LH & 6.60 & 12.00 & 47.29 & 1538.96 \\
4 & 38 & RH & 6.60 & 12.00 & 40.85 & 1329.10 \\
5 & 32 & LH & 6.50 & 12.00 & 33.89 & 882.03 \\
6 & 26 & RH & 6.50 & 12.00 & 27.56 & 678.49 \\
7 & 20 & LH & 6.50 & 12.00 & 21.23 & 489.67 \\
8 & 14 & RH & 6.60 & 12.00 & 15.15 & 85.05 \\
Core & 7 & - & 4.00 & 8.57 & - & 144.33 \\
& 7 & - & 5.20 & 8.03 & - & 39.02 \\
& 7 & - & 5.20 & 4.92 & - & 39 \\
\hline
\end{tabular}

Table 2 Construction details for the $127\left(\alpha=18^{\circ}\right) \mathrm{mm}$ outside diameter spiral strand

\begin{tabular}{|c|c|c|c|c|c|c|}
\hline Layer & $\begin{array}{l}\text { Number of } \\
\text { wires } n\end{array}$ & Lay direction & $\begin{array}{l}\text { Wire diameter } \\
D(\mathrm{~mm})\end{array}$ & $\begin{array}{l}\text { Lay angle } \\
\text { (deg) }\end{array}$ & $\begin{array}{l}\text { Pitch circle radius } \\
\text { (theoretical) } r(\mathrm{~mm})\end{array}$ & $\begin{array}{l}\text { Net steel area } \\
A_{\mathrm{n} i}\left(\mathrm{~mm}^{2}\right)\end{array}$ \\
\hline 1 & 54 & $\mathrm{RH}$ & 6.55 & 18.0 & 59.22 & 1913.31 \\
\hline 2 & 48 & LH & 6.55 & 18.0 & 52.64 & 1700.72 \\
\hline 3 & 42 & LH & 6.55 & 18.0 & 46.07 & 1488.13 \\
\hline 4 & 36 & $\mathrm{RH}$ & 6.55 & 18.0 & 39.50 & 1275.54 \\
\hline 5 & 31 & LH & 6.55 & 18.0 & 34.02 & 1098.38 \\
\hline 6 & 25 & $\mathrm{RH}$ & 6.55 & 18.0 & 27.46 & 885.79 \\
\hline 7 & 19 & LH & 6.55 & 18.0 & 20.90 & 673.20 \\
\hline 8 & 14 & $\mathrm{RH}$ & 6.30 & 18.0 & 14.85 & 458.90 \\
\hline \multirow[t]{4}{*}{ Core } & 7 & - & 3.90 & 13.07 & - & 77.29 \\
\hline & 7 & - & 5.10 & 12.20 & - & 133.53 \\
\hline & 7 & - & 5.25 & 7.62 & - & 142.55 \\
\hline & 1 & - & 7.00 & - & & 38.49 \\
\hline
\end{tabular}


Table 3 Construction details for the $127\left(\alpha=24^{\circ}\right) \mathrm{mm}$ outside diameter spiral strand

\begin{tabular}{|c|c|c|c|c|c|c|}
\hline Layer & $\begin{array}{l}\text { Number of } \\
\text { wires } n\end{array}$ & Lay direction & $\begin{array}{l}\text { Wire diameter } \\
D(\mathrm{~mm})\end{array}$ & $\begin{array}{l}\text { Lay angle } \\
\text { (deg) }\end{array}$ & $\begin{array}{l}\text { Pitch circle radius } \\
\text { (theoretical) } r(\mathrm{~mm})\end{array}$ & $\begin{array}{l}\text { Net steel area } \\
A_{\mathrm{n} i}\left(\mathrm{~mm}^{2}\right)\end{array}$ \\
\hline 1 & 54 & $\mathrm{RH}$ & 6.40 & 24.0 & 60.23 & 1901.58 \\
\hline 2 & 48 & LH & 6.40 & 24.0 & 53.54 & 1690.29 \\
\hline 3 & 42 & $\mathrm{LH}$ & 6.50 & 24.0 & 47.58 & 1525.58 \\
\hline 4 & 36 & $\mathrm{RH}$ & 6.50 & 24.0 & 40.79 & 1307.64 \\
\hline 5 & 30 & $\mathrm{LH}$ & 6.60 & 24.0 & 34.53 & 1123.49 \\
\hline 6 & 24 & $\mathrm{RH}$ & 6.60 & 24.0 & 27.64 & 898.79 \\
\hline 7 & 18 & $\mathrm{LH}$ & 6.80 & 24.0 & 21.38 & 715.57 \\
\hline 8 & 14 & $\mathrm{RH}$ & 6.10 & 24.0 & 14.94 & 447.87 \\
\hline \multirow[t]{4}{*}{ Core } & 7 & - & 3.90 & 17.89 & - & 72.07 \\
\hline & 7 & - & 5.10 & 16.75 & - & 125.56 \\
\hline & 7 & - & 5.25 & 10.58 & - & 143.94 \\
\hline & 1 & - & 7.00 & - & - & 38.49 \\
\hline
\end{tabular}

Table 4 Values of the full-slip and no-slip constitutive constants for the three $127 \mathrm{~mm}$ outside diameter spiral strands, with lay angles of $12^{\circ}$, $18^{\circ}$, and $24^{\circ}$

\begin{tabular}{lllllr}
\hline & $\begin{array}{l}\text { Lay } \\
\text { angle } \\
(\mathrm{deg})\end{array}$ & $\begin{array}{l}d_{1} \\
\left(\mathrm{~mm}^{2}\right)\end{array}$ & $\begin{array}{l}d_{2} \\
\left(\mathrm{~mm}^{3}\right)\end{array}$ & $\begin{array}{l}d_{3} \\
\left(\mathrm{~mm}^{3}\right)\end{array}$ & \multicolumn{1}{l}{$\begin{array}{l}d_{4} \\
\left(\mathrm{~mm}^{4}\right)\end{array}$} \\
\hline Full-slip & 12 & 8837 & -2576 & -3012 & 928782 \\
& 18 & 6860 & -3603 & -4326 & 1838043 \\
& 24 & 4520 & -4889 & -5193 & 3104408 \\
No-slip & 12 & 9380 & -1325 & -784 & 3447433 \\
& 18 & 8374 & -1770 & -429 & 3878215 \\
& 24 & 7491 & -2879 & -827 & 4693255 \\
\hline
\end{tabular}

should be noted that, particularly, the no-slip values of $d_{2}$ and $d_{3}$ in Table 4 are (at first sight) not close to each other. This is due to the rather small values of these constants in the nominally torsionally balanced spiral strands in which, although the no-slip $d_{2}$ and $d_{3}$ constants for individual layers, as fully reported by Kraincanic [24], were, indeed, found to be fairly similar, the accumulation of small errors in the course of algebraically adding up the contributions of the counter-laid layers in order to predict the overall values for the whole strand has led to such apparent (although not practically significant) anomalies. Indeed, in these nominally torsionally balanced spiral strands, the axial-torsional coupling is very weak. Because of the very small values of the coupling terms $A_{2}$ and $A_{3}$, even when using the complex (but more accurate) formulations of Raoof and Hobbs $[\mathbf{1}, \mathbf{2 3}]$, the computer program needed to be run with double precision in order to obtain reasonable values of the no-slip stiffness coefficients $A_{2}$ and $A_{3}$.

Table 5 gives estimates of the parameters, $\omega_{1}$ and $\omega_{2}$, axial or torsional wave speeds, $C_{1}$ and $C_{2}$, as well as the ratios of torsional to extensional amplitudes, $R_{1}$ and $R_{2}$, corresponding to both the no-slip and the full-slip regimes for the three $127 \mathrm{~mm}$ outside diameter spiral strands. Practically significant differences are found between the no-slip and full-slip solutions in all cases, with Table 5 showing the rather significant extent by which certain wave characteristics (such as amplitudes and speeds) differ for $12^{\circ} \leqslant \alpha \leqslant 24^{\circ}$, depending on whether the full-slip or

Table 5 Numerical results for the axial or torsional wave speeds $C_{1}$ and $C_{2}$, the ratios of torsional-extensional amplitudes $R_{1}$ and $R_{2}$, and the parameters $\omega_{1}$ and $\omega_{2}$, for the three $127 \mathrm{~mm}$ outside diameter and axially pre-loaded spiral strands, based on the no-slip and full-slip assumptions

\begin{tabular}{|c|c|c|c|c|c|c|}
\hline & \multicolumn{6}{|c|}{$127 \mathrm{~mm}$ outside diameter spiral strand } \\
\hline & \multicolumn{2}{|c|}{$\alpha=12^{\circ}$} & \multicolumn{2}{|c|}{$\alpha=18^{\circ}$} & \multicolumn{2}{|c|}{$\alpha=24^{\circ}$} \\
\hline & Full-slip & No-slip & Full-slip & No-slip & Full-slip & No-slip \\
\hline$C_{1}(\mathrm{~m} / \mathrm{s})$ & 4197.18 & 4324.20 & 3742.83 & 4134.65 & 3023.36 & 3889.41 \\
\hline$C_{2}(\mathrm{~m} / \mathrm{s})$ & 1080.25 & 2082.23 & 1567.88 & 2279.13 & 1988.52 & 2448.77 \\
\hline$R_{1}$ & -0.230 & -0.069 & -0.502 & -0.048 & -1.283 & -0.109 \\
\hline$R_{2}$ & 3202.91 & 5439.06 & 1569.83 & 3293.49 & 524.02 & 1570.37 \\
\hline$\omega_{1}(\mathrm{~s})$ & 0.002383 & 0.002313 & 0.002672 & 0.002419 & 0.003308 & 0.002571 \\
\hline$\omega_{2}(\mathrm{~s})$ & 0.009257 & 0.004803 & 0.006378 & 0.004388 & 0.005029 & 0.004084 \\
\hline
\end{tabular}


the no-slip solution is adopted. It should be pointed out that all the axial-torsional wave characteristics given in Table 5 are independent of the specific form of impact loading at the end of the spiral strand.

Before presenting the rest of the numerical results relating to various wave propagation characteristics of the $127 \mathrm{~mm}$ diameter strands (which follow next), it is perhaps worth mentioning that, for the present purposes, it will (in all cases) be assumed (as a reasonable first step) that $F_{0}$ is finite and $M_{0}=0$; i.e. a purely axial type of impulse will be assumed. This, obviously, only models the situation where (strictly speaking) the straight King wire in a strand breaks. In practice, however, for breakages of individual helical wires in any layer of a spiral strand, $M_{0}$ is not zero and will vary depending upon the location in the strand and the direction of lay. The presently proposed formulations can, however, cater for those cases when $M_{0}$ is not zero. In such cases, the simple approach proposed by Hruska [25] may be used (for a given strand axial strain) to calculate a reasonable value of the axial force in a given helical wire in layer $i$ of the spiral strand, $F_{i}$, with

$$
F_{0}=F_{i} \cos \alpha_{i}
$$

and, following Hruska [26],

$$
M_{0}=F_{i} r_{i} \sin \alpha_{i}
$$

where $r_{i}$ and $\alpha_{i}$ are the helix radius and the lay angle respectively for layer $i$, with $\alpha$ being positive for the right-hand lay. Once $F_{0}$ and its associated $M_{0}$ are estimated, equations (22) and (23) [with the appropriate form of $g(t)]$ may then be used to define the resulting impulse.

Bearing the above comments in mind, for illustrative purposes, Figs 1(a) to (c) show the variations of the axial displacements at time $t=0.001163 \mathrm{~s}$ along the length of the $127 \mathrm{~mm}\left(\alpha=12^{\circ}\right)$ diameter cable for both the full-slip and the no-slip regimes, with the end of the cable, at position $X=0$, fixed and the other end of the cable at $X=10 \mathrm{~m}$ subjected to unit-step, triangular, and half-sine impact loading functions respectively, with the duration of the impact load $A=0.00052 \mathrm{~s}, F_{0}=50 \mathrm{kN}$, and $M_{0}=0$. Figures $1(\mathrm{~d}$ ) to (f) show the corresponding rotational displacements along the length of this same cable for the three loading functions respectively, at time $t=0.001163 \mathrm{~s}$, based on the full-slip and the no-slip regimes, as a function of the distance, $X$, along the cable. Figures 2 (a) to (c) compare the variations of the axial displacements, as a function of time, at the centre $(X=5 \mathrm{~m})$ of the $127 \mathrm{~mm}\left(\alpha=12^{\circ}\right)$ diameter cable for the unit-step, triangular, and half-sine impact loading functions for both the full-slip and no-slip regimes.
Figures 2(d) to (f) show the corresponding rotational displacements, as a function of time, at the centre of this same cable for the three impact loading functions, based on the full-slip and no-slip regimes.

Figures 3(a) to (c) and 4(a) to (c) and Figs 3(d) to (f) and $4(\mathrm{~d})$ to (f) show the variations of the axial and rotational displacements respectively, as a function of the distance along the cable and as a function of time at the centre of the cable, for the $127 \mathrm{~mm}$ $\left(\alpha=18^{\circ}\right)$ diameter cable. Similarly, Figs 5(a) to (c) and 6(a) to (c) and Figs 5(d) to (f) and 6(d) to (f) show the variations of the axial and rotational displacements respectively, as a function of the distance along the cable and as a function of time at the centre of the cable, for the $127 \mathrm{~mm}\left(\alpha=24^{\circ}\right)$ diameter cable. In all the plots in Figs 1 to 6 , the same values of $F_{0}=50 \mathrm{kN}, M_{0}=0, A=0.00052 \mathrm{~s}$, and $t=0.001163 \mathrm{~s}$ have been assumed. It is, perhaps, worth mentioning that the time $t=0.001163 \mathrm{~s}$ and the assumed values of $F_{0}=50 \mathrm{kN}, M_{0}=0$, and $A=0.00052 \mathrm{~s}$ are the same as those used for the numerical results presented in reference [19] which related to a $39 \mathrm{~mm}$ outside diameter spiral strand with different magnitudes of lay angles in its various layers. This is meant to facilitate the comparison of the plots in reference [19] and in the present paper.

Once again, from the graphical results it is evident that some rather significant differences exist between the full-slip and no-slip wave propagation characteristics. An important observation is that as the lay angle increases, within the practical limits, the differences between the corresponding full-slip and no-slip wave propagation characteristics become increasingly more pronounced.

\section{DISCUSSION}

Traditional theoretical solutions have invariably adopted the full-slip assumption which, although valid for large levels of external loading and/or newly manufactured (but prestretched) helically wound cables [27], fail to provide accurate predictions for cases when the amplitudes of externally applied impact loads on fully bedded-in and axially preloaded cables are fairly small. Such cases occur in connection with the calibration of non-destructive monitoring devices for in situ detection of individual wire fractures under, say, axial fatigue loading, whereby the fracture of an individual wire sends a small but measurable shock wave(s) along the cable which is picked up by the electronic boxes. Most importantly, the present results throw considerable doubt on the validity of the traditional methods 

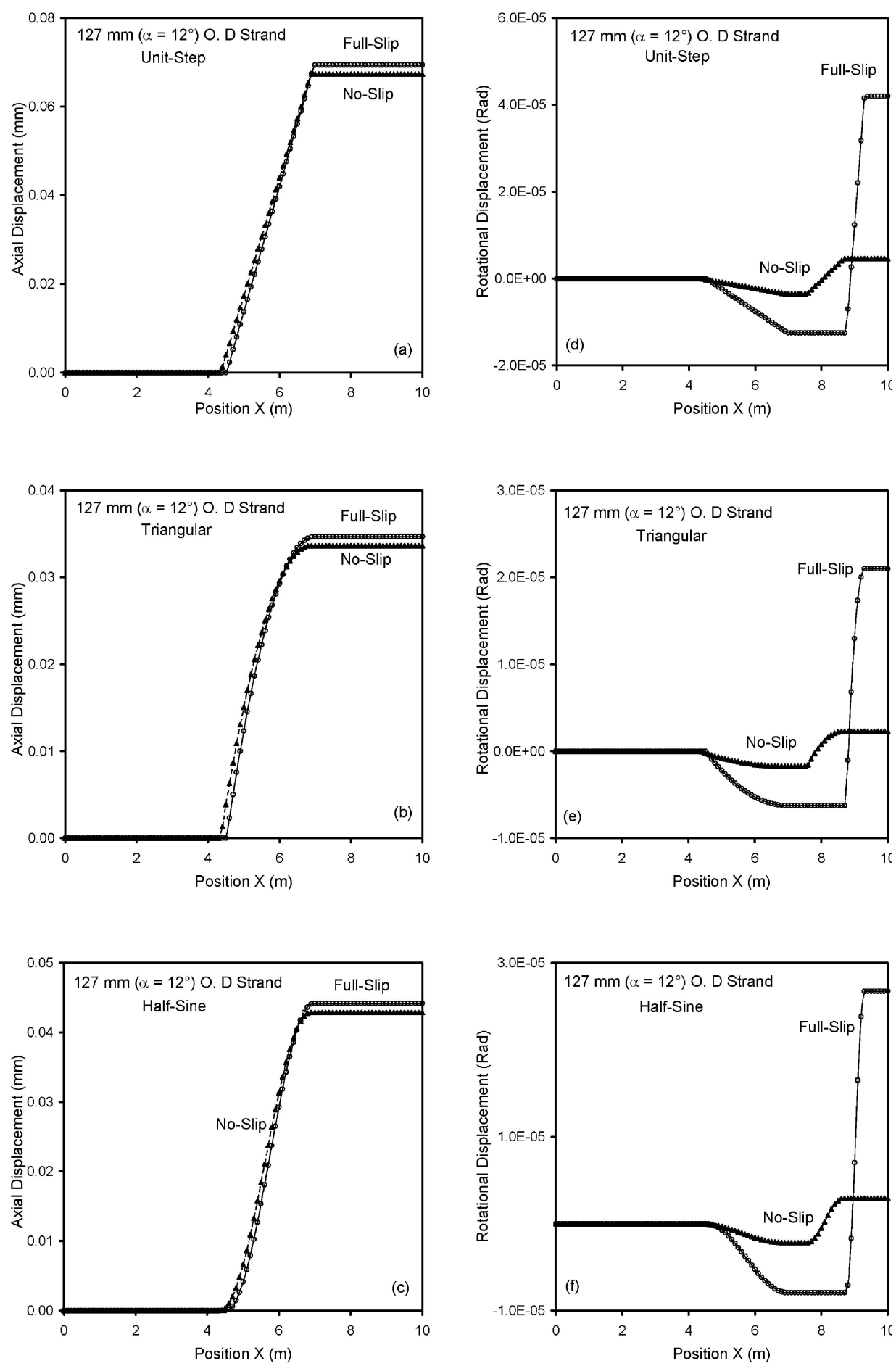

Fig. 1 Comparison of the axial and rotational displacements, along the cable at time $t=0.001163$ (s), subjected to an impact load of duration $A=0.00052$ (s) for the no-slip and full-slip conditions: (a, d) unit-step loading function; (b, e) triangular loading function; and $(\mathrm{c}, \mathrm{f})$ half-sine loading function $-127 \mathrm{~mm}\left(\alpha=12^{\circ}\right)$ spiral strand

for calibrating such electronic boxes. Very briefly, instrumentation experts calibrate their devices by picking up what they call significant effects (such as amplitudes or other effective acoustic signal discriminators such as the frequency components of singular wire fractures within a rope), which are (under laboratory conditions) often simulated by deliberately fracturing a wire in a newly manufactured 

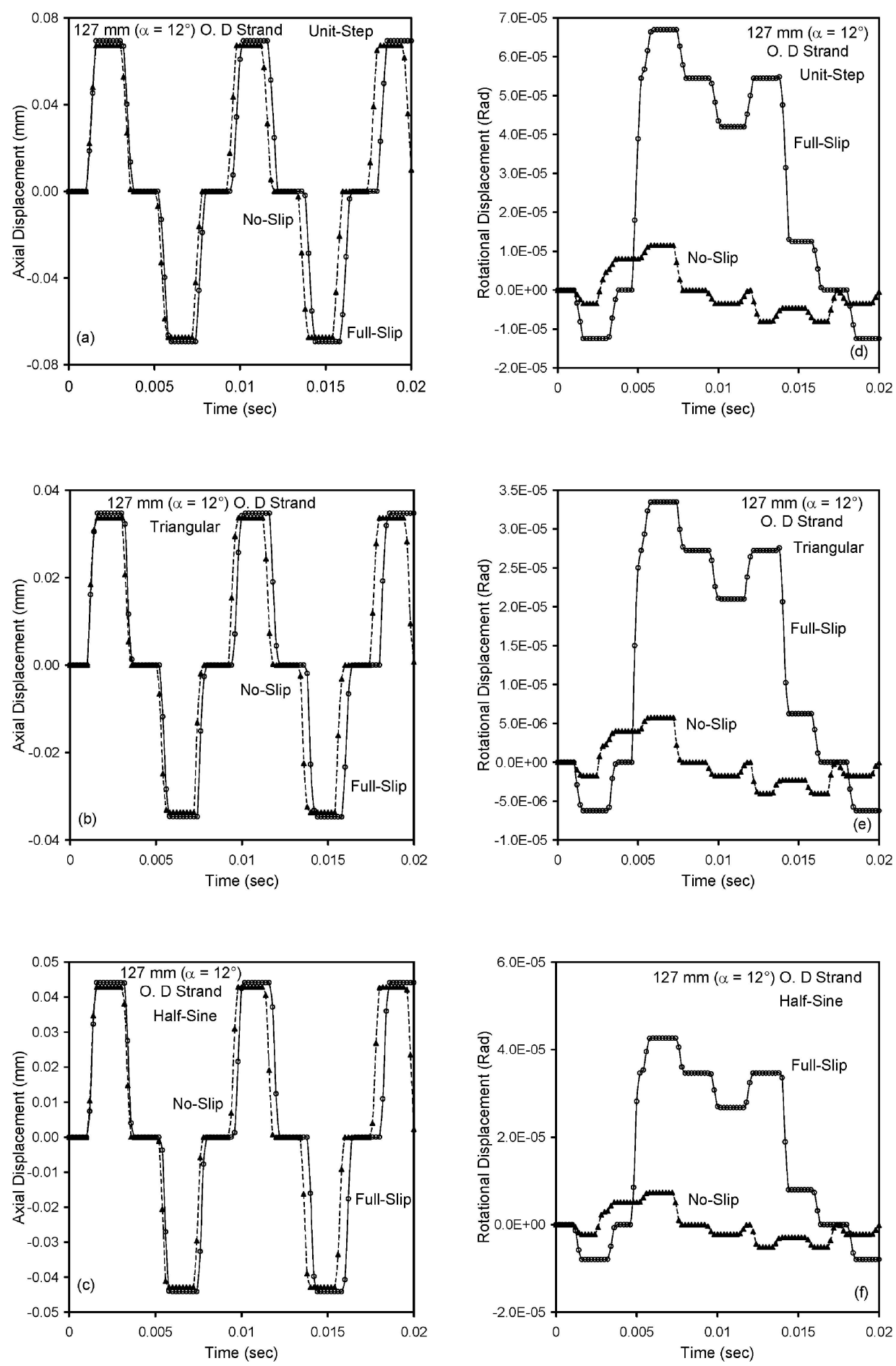

Fig. 2 Comparison of the axial and rotational displacements, at the middle point of the cable $X=5 \mathrm{~m}$, as a function of time, subjected to an impact load of duration $A=0.00052$ (s) for the no-slip and full-slip conditions: (a,d) unit-step loading function; (b, e) triangular loading function; and (c, f) half-sine loading function $-127 \mathrm{~mm}\left(\alpha=12^{\circ}\right)$ spiral strand

and axially loaded cable at the end of which the electronic box signals (waves) are picked up (e.g. [28-30]). In this context, the works of Casey et al. (e.g. $[\mathbf{2 8}, \mathbf{2 9}])$ may be mentioned, which con- centrated on the acoustic emission amplitude distributions and the frequency components of singular wire fractures within a wire rope and concluded that high amplitude hits could be associated with 

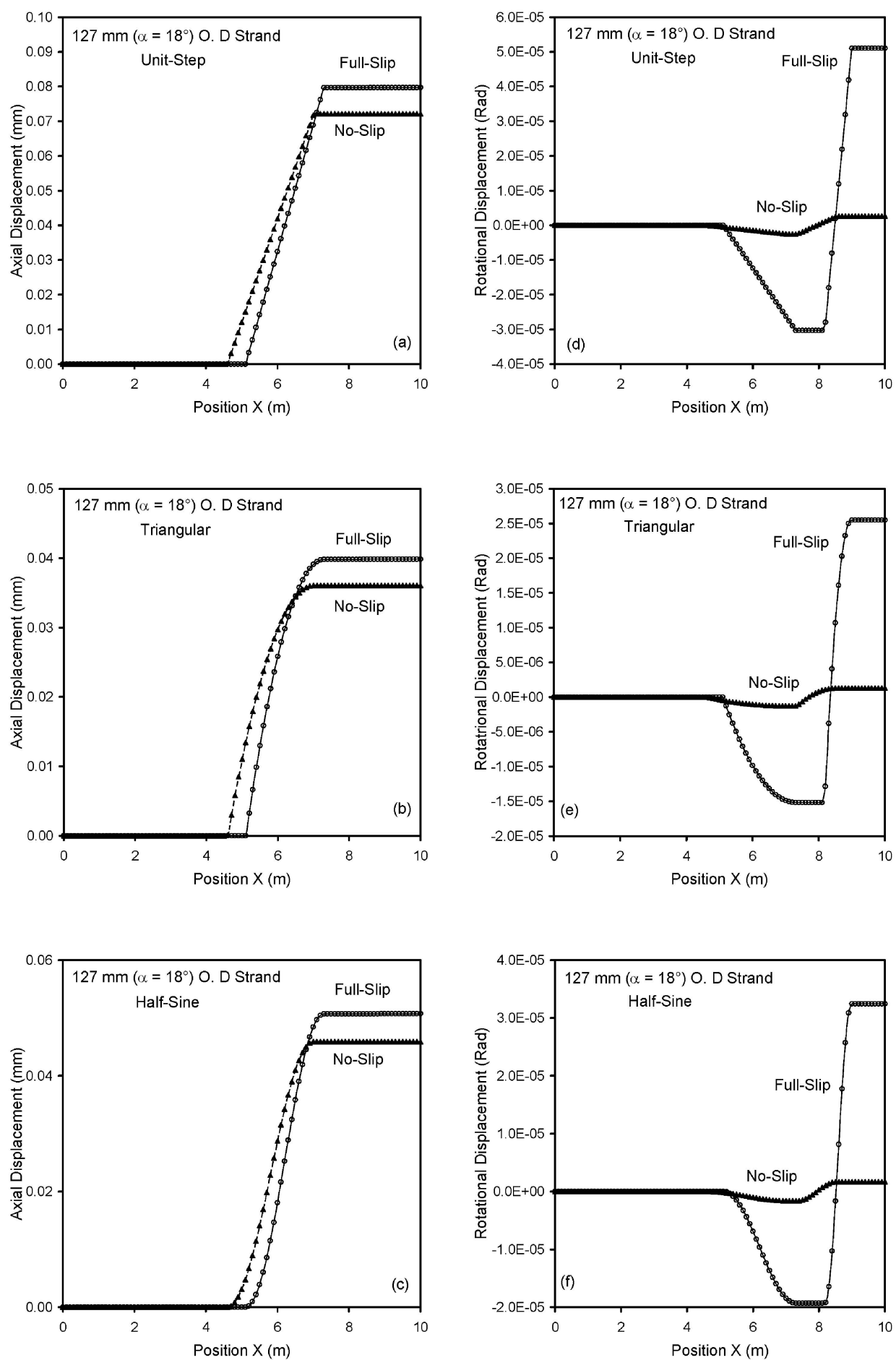

Fig. 3 Comparison of the axial and rotational displacements, along the cable at time $t=0.001163$ (s), subjected to an impact load of duration $A=0.00052$ (s) for the no-slip and full-slip conditions: (a, d) unit-step loading function; (b, e) triangular loading function; and $(\mathrm{c}, \mathrm{f})$ half-sine loading function $-127 \mathrm{~mm}\left(\alpha=18^{\circ}\right)$ spiral strand

wire fractures - attaining a one-to-one correlation between hits and wire breaks. However, in old and fully bedded-in cables in practice, the cable structure is compacted in such a way that (with an individual wire carrying a small fraction of the total axial load on the cable) the amplitudes and speeds of the axial and torsional waves released by the fracture of an individual wire are governed (because of 

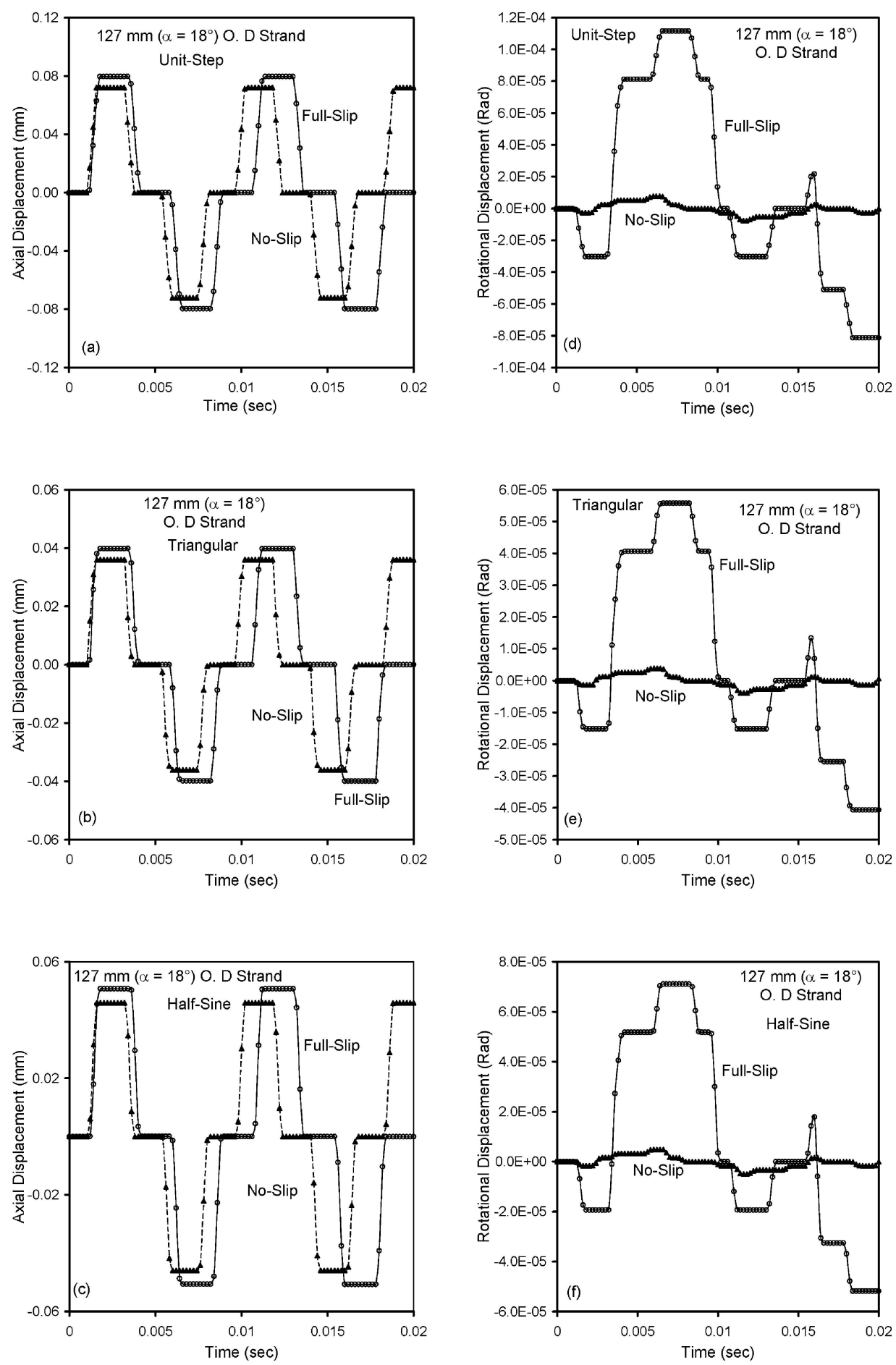

Fig. 4 Comparison of the axial and rotational displacements, at the middle point of the cable $X=5 \mathrm{~m}$, as a function of time, subjected to an impact load of duration $A=0.00052$ (s) for the no-slip and full-slip conditions: (a, d) unit-step loading function; (b, e) triangular loading function; and (c, f) half-sine loading function $-127 \mathrm{~mm}\left(\alpha=18^{\circ}\right)$ spiral strand

their small magnitudes) by the no-slip stiffnesses, which are significantly different from the full-slip stiffnesses that govern the behaviour of newly manufactured cables [27] originally used for calibrating the electronic boxes. It is therefore suggested that caution should be exercised in interpreting the data obtained from such devices under service conditions using the traditional methods of calibration based on the 

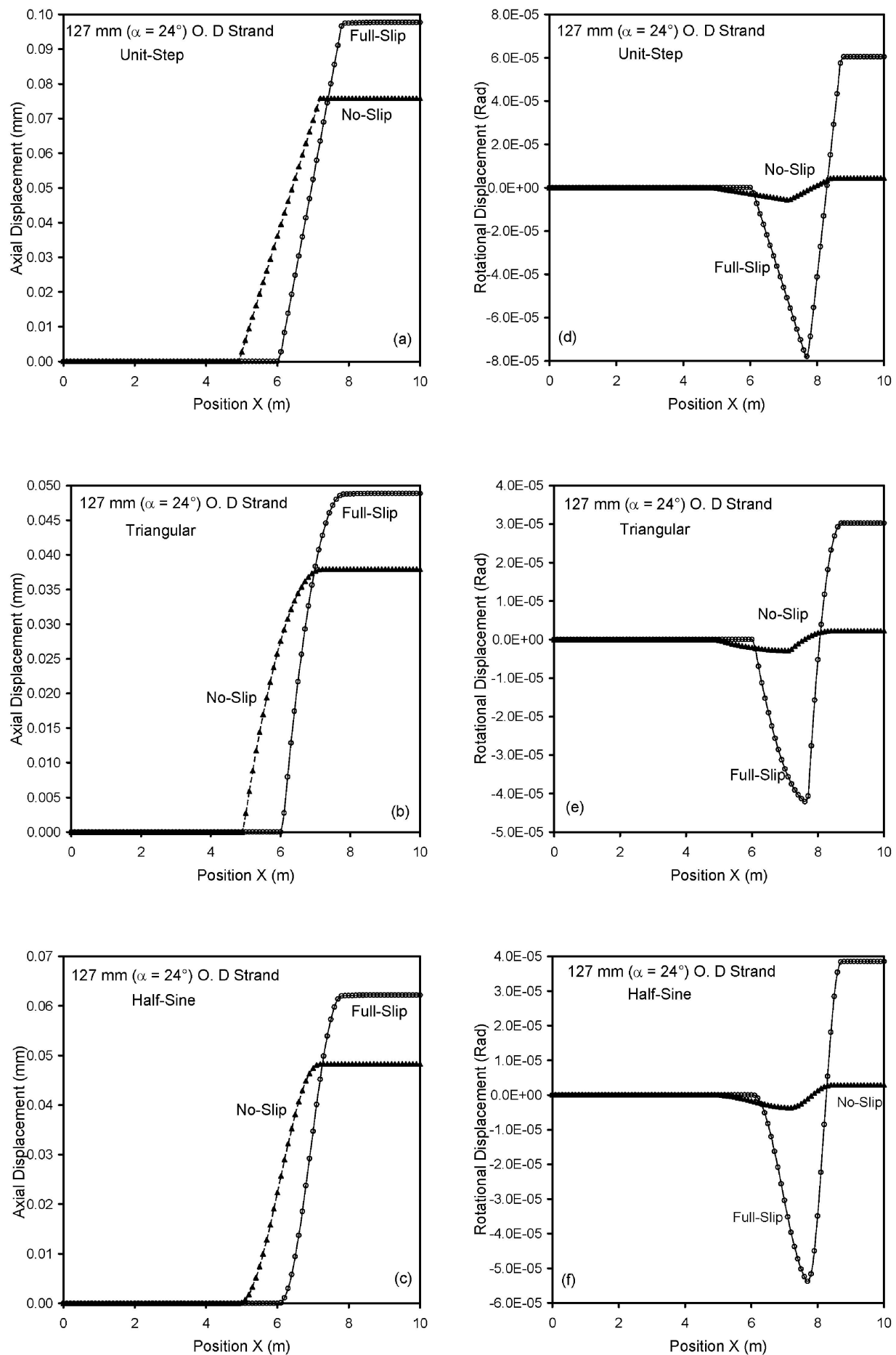

Fig. 5 Comparison of the axial and rotational displacements, along the cable at time $t=0.001163$ (s), subjected to an impact load of duration $A=0.00052$ (s) for the no-slip and full-slip conditions: (a, d) unit-step loading function; (b, e) triangular loading function; and (c, f) half-sine loading function $-127 \mathrm{~mm}\left(\alpha=24^{\circ}\right)$ spiral strand

full-slip behaviour of newly manufactured cables. In the previous section, the full-slip wave characteristics, such as amplitudes and speeds, are theoretically shown to be significantly different from the corre- sponding no-slip wave characteristics for a number of assumed (namely unit-step, triangular, and half-sine) loading functions. It is therefore suggested that such electronic devices should be calibrated using well 

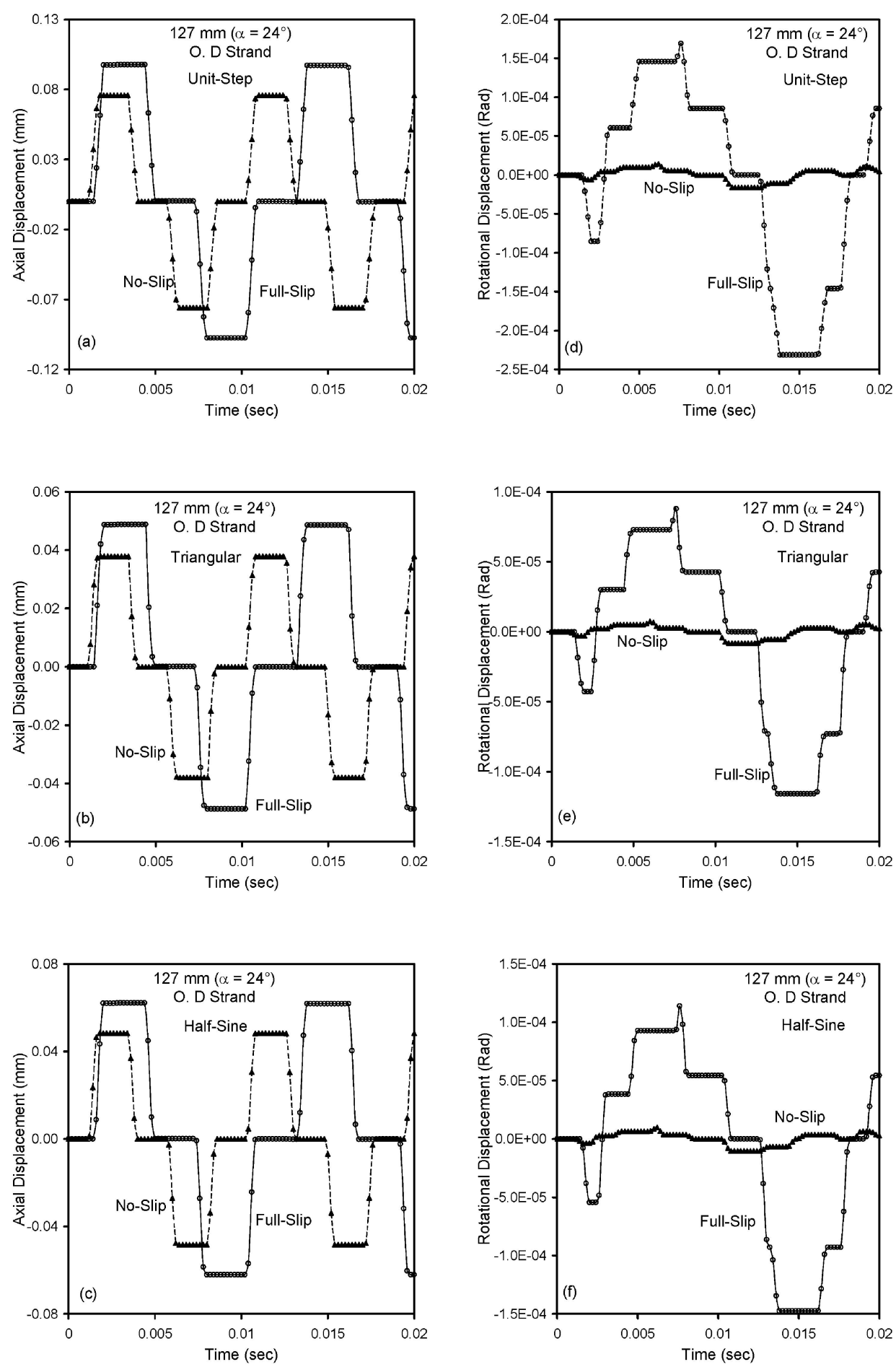

Fig. 6 Comparison of the axial and rotational displacements, at the middle point of the cable $X=5 \mathrm{~m}$, as a function of time, subjected to an impact load of duration $A=0.00052$ (s) for the no-slip and full-slip conditions: (a,d) unit-step loading function; (b, e) triangular loading function; and (c, f) half-sine loading function $-127 \mathrm{~mm}\left(\alpha=24^{\circ}\right)$ spiral strand

bedded-in (old) helically wound cables that have seen service conditions for a number of years. It is, perhaps, also worth mentioning that the exact form of the loading function relating to the sudden fracture of a wire inside the cable obviously remains unpredictable and very difficult (if at all possible) to determine, using the currently available experimental techniques. However, the use of widely 
different forms of impact loading functions, as adopted in the present work, should reasonably cover the range of possibilities, and the final results based on all three types of such impact loading functions have invariably supported the view that the no-slip wave propagation characteristics are, indeed, significantly different from the corresponding full-slip ones, and therefore the non-destructive monitoring 'electronic boxes' should be calibrated by using fully bedded-in samples.

Finally, it should be noted that the numerical results presented in the previous section are for $10 \mathrm{~m}$ long spiral strands. In offshore applications, however, steel cables are typically hundreds of metres long and not straight. There may also be a variation in tension along the cable owing to its own self-weight. These are not, however, an issue with bridge cables. The underlying reason for choosing a $10 \mathrm{~m}$ (i.e. not very long) spiral strand in the present numerical examples is the fact that, in practice, due to the everpresent significant levels of interwire friction and intrinsic material damping in helically wound steel cables, there will be a very significant degree of wave attenuation particularly in very long cables. Because of the neglect of damping in the present proposed formulations, the results will only be applicable to fairly short cables such as those employed in bridging applications. The present authors are the first to admit that the present work does not provide answers to all the questions as regards wave propagations in cables. They do, however, believe that the present work constitutes an advancement over what was previously available in the literature. Although damping is, for example, ignored in the present work, the nature of the presently proposed formulations makes inclusion of damping in the present work mathematically tractable, and this will be the subject of future work. For the time being, the present work has clearly demonstrated, for example, that the electronic boxes should be calibrated by using fully bedded-in (old) samples, which becomes a more critical issue as the magnitudes of the lay angles in a spiral strand increase. Although, at first sight, perhaps not surprising, it should be borne in mind that these crucial facts had, as evident in the available literature, previously been completely ignored in the rather elaborate experimental and/or theoretical works reported by others working in this area.

\section{CONCLUSIONS}

The current analysis extends the previously reported work of Raoof and his associates, who developed closed-form solutions for predicting the various characteristics of coupled extensional-torsional waves induced by unit-step and triangular forms of impact loading at one end of helically wound steel cables (spiral strands and wire ropes) with the other end fixed against any movement, to include the solution for half-sine types of impact loading. Detailed numerical results based on three different $127 \mathrm{~mm}$ outside diameter spiral strands with widely varying lay angles (within the current manufacturing limits) are presented, which demonstrate the significant effects of variations in the lay angle on the various wave propagation characteristics of axially pre-loaded spiral strands.

Significant differences have been found between a number of axial-torsional wave characteristics induced in axially pre-loaded spiral strands subjected to unit-step, triangular, and half-sine forms of impact loading functions, depending on whether the no-slip or the traditionally adopted full-slip version of the constitutive relations are used in the analysis. It is argued that, due to the ever-present interwire friction, for sufficiently small levels of load perturbations (due to the fracture of an individual wire) applied to fully bedded-in (old) and axially pre-loaded cables, the no-slip version of the constitutive relations should be used. The use of the no-slip version of the constitutive relations is shown to become more critical as (for a given spiral strand) the lay angles increase. The present findings may have significant practical implications in relation to the currently adopted techniques by industry for calibrating the electronic boxes, which are subsequently used for the in situ detection of individual wire fractures under, say, fatigue loading associated with cable supported structures. It has now been demonstrated that such systems should be calibrated by using fully bedded-in (as opposed to newly manufactured but pre-streched) samples, with their associated wave propagation characteristics governed by the no-slip (rather than the full-slip) cable stiffness characteristics. This issue becomes more critical with increasing magnitudes of the lay angle in various layers of a spiral strand.

\section{REFERENCES}

1 Raoof, M. and Hobbs, R. E. Analysis of multi-layered structural strands. J. Engng Mechanics, ASCE, July 1988, 114(7), 1166-1182.

2 Raoof, M. and Huang, Y. P. Axial and free bending analysis of spiral strands made simple. J. Engng Mechanics, ASCE, December 1992, 118(12), 23352351. 
3 Raoof, M. and Kraincanic, I. Analysis of large diameter steel ropes. J. Engng Mechanics, ASCE, June 1995, 121(6), 667-675.

4 Strzemiecki, J. and Hobbs, R. E. Properties of wire rope under various fatigue loadings. CESLIC Report SC6, Engineering Structures Laboratories, Department of Civil Engineering, Imperial College, London, 1988.

5 Raoof, M. and Davies, T. J. Simple determination of the axial stiffness for large diameter independent wire rope core or fibre core wire ropes. J. Strain Analysis, November 2003, 38(6), 577-586.

6 Costello, G. A. and Miller, R. E. Static response of reduced rotation rope. J. Engng Mechanics, ASCE, 1980, 106(EM4), 623-631.

7 Velinsky, S. A., Anderson, G. L., and Costello, G. A. Wire rope with complex cross sections. J. Engng Mechanics, ASCE, March 1984, 110(3), 380-391.

8 Velinsky, S. A. General non-linear theory for complex wire rope. J. Mech. Sci., 1985, 27(7/8), 497-507.

9 Jiang, W. A general formulation of the theory of wire ropes. Trans. ASME, J. Appl. Mechanics, September 1995, 62, 747-755.

10 Goeller, J. E. and Laura, P. A. Dynamic stress and displacements in a two-material cable system subjected to longitudinal excitation. J. Acoust. Soc. Am., 1969, 46, 284-292.

11 Liu, C. L. Dynamic stress response of lifting lines for oceanic operations. Technical Report R-703, Naval Civil Engineering Laboratories, Port Hueneme, California, 1970.

12 Nath, J. H. Dynamic response of taut lines for buoys. Mar. Technol. Soc. J., 1971, 5(4), 44-46.

13 Samras, R. K., Skop, R. A., and Milburn, D. A. An analysis of coupled extensional-torsional oscillations in wire rope. Trans. ASME, J. Engng for Industry, November 1974, 74, 1130-1135.

14 Skop, R. A. and Samras, R. K. Effects of coupled extensional-torsional oscillations in wire rope during ocean salvage and construction operations. Trans. ASME, J. Engng for Industry, May 1975, 97, 485-492.

15 Phillips, J. W. and Costello, G. A. Axial impact of twisted wire cables. Trans. ASME, J. Appl. Mechanics, March 1977, 44, 127-131.

16 Leech, C. M. and Overington, M. S. The dynamics of wire rope subjected to shock axial loads. In Proceedings of the 14th Annual Offshore Technology Conference, Houston, Texas, 1982.

17 Martin, P. A. and Berger, J. R. On mechanical waves along aluminium conductor steel reinforced (ACSR) powerlines. Trans. ASME, J. Appl. Mechanics, November 2002, 69, 740-748.

18 Jolicoeur, C. and Cardou, A. Semi-continuous mathematical model for bending of multilayered wire strands. J. Engng Mechanics, ASCE, July 1996, 122(7), 643-650.

19 Raoof, M., Huang, Y. P., and Pithia, K. D. Response of axially preloaded spiral strands to impact loading. Computers and Structs, 1994, 51(2), 125-135.

20 Jiang, W., Wang, T. L., and Jones, W. K. Forced vibration of coupled extensional-torsional systems. J. Engng Mechanics, ASCE, May 1990, 117(5), 1171-1190.

21 Raoof, M. Methods for analysing large spiral strands. J. Strain Analysis, 1991, 26(3), 165-174.

22 Raoof, M. and Kraincanic, I. Simple derivation of the stiffness matrix for axial/torsional coupling of spiral strands. Computers and Structs, 1995, 55(4), 589-600.

23 Raoof, M. and Hobbs, R. E. Torsional stiffness and hysteresis in spiral strands. Proc. Instn Civ. Engrs, Part II, December 1989, 87 501-515.

24 Kraincanic, I. Analysis of the coupled axial/torsional behaviour of spiral strands, wire ropes, and locked coil cables, PhD thesis, submitted to South Bank University, London, 1995.

25 Hruska, F. H. Calculation of stresses in wire ropes. Wire and Wire Products, 1951, 26, 766-767 and 799-801.

26 Hruska, F. H. Tangential forces in wire ropes. Wire and Wire Products, 1953, 28, 455-460.

27 Raoof, M. Comparison between the performance of newly manufactured and well-used spiral strands. Proc. Insth Civ. Engrs, Part II, March 1990, 89, 103-120.

28 Casey, N. F., Taylor, J. L., and Holford, K. M. Wire break detection during tensile fatigue testing of $40 \mathrm{~mm}$ wire rope. Br. J. Non-Destructive Testing, 1985, 30(5), 338-341.

29 Casey, N. F., White, H., and Taylor, J. L. Frequency analysis of the signals generated by the failure of constituent wires of wire rope. NDT Int., December 1985, 18(6), 339-344.

30 Casey, N. F. and Laura, P. A. A. A review of the acoustic monitoring of wire rope. Ocean Engng, 1997, 24(10), 935-947.

\section{APPENDIX}

\section{Notation}

A

$A_{\mathrm{n} i}$

$A_{\mathrm{s}}$

$A_{1}, A_{2}, A_{3}, A_{4}$ $C_{1}, C_{2}$

$d_{1}, d_{2}, d_{3}, d_{4}$

$D_{i}$

$E_{\mathrm{s}}$

F

$F_{0}$ duration of impact loading net steel area in layer $i$ total net steel area (including the core) in a spiral strand constitutive constants speeds of axial waves, associated with which there are torsional waves with the same speeds, $C_{1}$ and $C_{2}$, respectively $=A_{1} / E_{\mathrm{s}}, A_{2} / E_{\mathrm{s}}, A_{3} / E_{\mathrm{s}}, A_{4} / E_{\mathrm{s}}$ respectively wire diameter in layer $i$ Young's modulus of steel axial force axial amplitude of external impact loading 


\begin{tabular}{|c|c|c|c|}
\hline$h$ & length of the cable & $t$ & time \\
\hline$I$ & mass moment of inertia about the & $u$ & axial displacement of the cable \\
\hline & cable axis & $x$ & coordinate along the cable \\
\hline$k$ & $=(2 n+1) \pi /(2 h)$ & & \\
\hline$m$ & mass of cable per unit length & $\alpha_{i}$ & lay angle in layer $i$ \\
\hline$M$ & torque & $\Gamma$ & twist per unit length $=\partial \theta / \partial x$ \\
\hline$M_{0}$ & torsional amplitude of external & $\varepsilon$ & cable axial strain $=\partial u / \partial x$ \\
\hline & impact loading & $\theta$ & rotational amplitude of the \\
\hline$n_{i}$ & number of wires in layer $i$ & & torsional wave \\
\hline$N$ & total number of layers of wires in & $\lambda_{i}$ & $=(2 n+1) \pi /\left(2 \omega_{i}\right)$ \\
\hline & a spiral strand excluding the core & $v$ & Poisson's ratio \\
\hline$r_{i}$ & helix radius in layer $i$ & $\rho$ & density of steel \\
\hline
\end{tabular}

